\title{
Emphysema in COPD: consequences and causes
}

\section{G M Turino}

\section{There is still much to be learned about the cellular and cytokine reactions of specific phenotypes in COPD}

$\mathrm{T}$ he current definition of chronic obstructive pulmonary disease (COPD), which has been established by the Global Initiative on Obstructive Lung Disease $(G O L D)^{1}$ and also adopted, in large part, by the American Thoracic Society and the European Respiratory Society, is that COPD is a "preventable and treatable disease state characterized by airflow limitation that is not fully reversible". This definition has the virtue of simplicity and clinical applicability but necessarily includes patients with widely varying clinical phenotypes and pathogenic mechanisms. The paper by Boschetto et $a l^{3}$ in this issue of Thorax focuses on the role of radiologically identified pulmonary emphysema in a group of patients diagnosed with COPD on the basis of their presenting clinical state and separated into groups for comparison between those with and without radiologically identified emphysema.

Patient selection began with 50 individuals with COPD who then underwent computed tomographic (CT) scanning with a third generation continuousrotation scanner. The quantitation of emphysema is well described and the quality of the CT scan obtained is considered adequate to rule out the presence of significant emphysema, ${ }^{3}$ which is essential for the premises of the study. Importantly, the smoking history between the two patient groups was not significantly different, which suggests varying host factors as causes for the differences observed. The characterisation of patients includes the BODE index, which includes body mass, air flow obstruction, dyspnoea severity, and exercise measured by the 6 minute walk test. ${ }^{4}$

This study shows that patients with CT confirmed emphysema have a higher BODE index and lower IC/TLC ratios than subjects without CT confirmed emphysema. Also, COPD patients with emphysema had lower levels of forced expiratory volume in 1 second $\left(\mathrm{FEV}_{1}\right)$, $\mathrm{FEV}_{1} /$ forced vital capacity, and carbon monoxide transfer coefficient and higher functional residual capacity, all of which were associated with an increase in eosinophils and increased matrix metalloproteinase (MMP)-9 concentrations and an increased MMP-9/ TIMP ratio in induced sputum.

This paper supports a previous study by Boschetto et al ${ }^{5}$ which demonstrated the more severely compromised physiological state of lung function in COPD patients with an emphysema phenotype with regard to airflow obstruction, hyperinflation, and reduced transfer factor.

A major strength of the study is the investigation of cell and molecular markers by sputum induction in an attempt to show distinguishing features in patients with and without emphysema. These markers are previously recognised pathogenic factors which have been investigated by bronchoalveolar lavage (BAL), ${ }^{6}$ but not using the findings in induced sputum to distinguish COPD with and without demonstrable emphysema.

\section{EOSINOPHILIA IN COPD}

A new and somewhat surprising finding in this study is the increased numbers of eosinophils in induced sputum in the emphysema group which has not been detected in previous BAL studies ${ }^{67}$ or in induced sputum of a previous study. ${ }^{5}$ Overall, eosinophilic inflammation of bronchi has been well documented in asthma by bronchial biopsies and $\mathrm{BAL},{ }^{8}$ and it is also a common finding in the sputum of asthmatic patients. ${ }^{9} 10$

In COPD, previous studies have described significant eosinophilia in bronchial biopsy specimens from patients with chronic bronchitis during exacerbation. ${ }^{11}$ Eosinophils were also observed in the sputum of patients with COPD not segregated into emphysema and nonemphysema groups during acute exacerbations. $^{12}$ In a study using induced sputum in non-atopic COPD patients in a stable state, eosinophilia was demonstrated and related to mast cell activation. ${ }^{13}$ Therapeutically, Brightling et al reported an increase in the sputum eosinophil count of patients with COPD in a randomised controlled trial which showed an increased beneficial response to corticosteroids in patients with increased eosinophil counts in blood and sputum. ${ }^{14}$ This study suggests that the airway inflammatory state in COPD is related to the eosinophilia. In a later study, Brightling et al showed an improvement in $\mathrm{FEV}_{1}$ post-bronchodilator after a 6 week course of inhaled mometasone in patients with eosinophilia in induced sputum of patients with COPD. ${ }^{15}$

The eosinophilia in the induced sputum of patients in this study must be viewed in the context of the "inflamed lung" in COPD. In this regard, the cellular profile in alveoli and small airways of COPD patients shows increases in macrophages, $\mathrm{T}$ lymphocytes (especially CD8 cells), B lymphocytes, and neutrophils. ${ }^{16}{ }^{17}$ Given the multiple possibilities for immunological interactions in the COPD lung parenchyma and airways, it is unclear whether eosinophilia in the emphysema group of this study arises from external antigens or cellular-cytokine reactions in situ. Therapeutically, it would be of interest to determine whether, even in the presence of predominant emphysema, there is increased responsiveness to corticosteroids in this phenotype.

\section{EMPHYSEMA AND MATRIX METALLOPROTEASES (MMPs)}

The study by Boschetto et al ${ }^{3}$ contributes additional evidence for the significant role of MMP-9 (gelatinase-B) among the enzymes which may induce emphysematous destruction. The MMPs are a homologous group of endopeptidases which are capable of degrading many of the constituents of the extracellular matrix including collagen, elastin, proteoglycans, laminin, and fibronectin, and are produced by the macrophages and neutrophils. ${ }^{18}$ Previous studies have shown an increase in MMP-9 in BAL fluid in patients with emphysema, ${ }^{67}$ and this study demonstrates the increase by a non-invasive method in induced sputum which justifies a greater use of induced sputum for such studies. Also, the MMP9 levels were higher in the COPD patients with emphysema than in those without emphysema, which is consistent with their possibly predominant pathogenic role. However, it is still likely that multiple proteases are involved in parenchymal degradation. In this regard, it should be recognised that MMPs degrade and inactivate $\alpha_{1}$-antitrypsin, thus increasing the activity of neutrophil elastase indirectly, together with other enzymes such as cathepsins..$^{19} 20$

ELASTIN DEGRADATION IN COPD Although desmosine levels in urine, plasma, and sputum were increased, they did not differ between patients with and without emphysema. This 
finding is not surprising since elastin is distributed in large measure beyond the alveoli to bronchial and vascular structures. The increased levels of desmosine in the non-emphysematous phenotype indicate that this marker may be useful for detecting tissue degradation in the non-emphysematous COPD phenotype. The improved technical ability to measure desmosine in sputum and plasma, as well as in urine, significantly increases its usefulness as a marker of lung matrix degradation and should be more widely applied in COPD.

\section{IMPLICATIONS OF THE STUDY}

Overall, this study presents several significant insights to delineate phenotypes within the broad category of COPD:

- CT scanning is essential for identifying COPD patients with and without a significant component of pulmonary emphysema.

- Induced sputum can yield characterising markers for various COPD phenotypes which may vary from the findings in BAL fluid. Where possible, studies should compare findings in sputum with those from BAL fluid in the same patients.

- While the patients in this study had moderate to severe COPD, studies in patients with mild or early COPD would be worthwhile to determine whether the same enzymatic and inflammatory mediators are detected in early disease.

- The source of increased levels of MMP-9 with respect to neutrophil versus macrophage should be better defined to identify possible therapeutic targets.

- The increase in eosinophils in induced sputum in the emphysema phenotype deserves study in larger series of patients to determine its consistency. Also, the significance of eosinophilia immunologically, functionally and pathologically needs to be better understood in COPD, especially in the emphysema phenotype.

The findings in this study indicate how much more we still need to learn about the cellular and cytokine reactions of specific phenotypes in COPD, and how they differ from the asthmatic state. $^{21}$

Thorax 2006;61:1031-1032.

doi: $10.1136 /$ thx.2006.066308

Correspondence to: $\operatorname{Dr} G M$ Turino, Department of Medicine, St Luke's-Roosevelt Hospital Center, 1000 Tenth Avenue, New York, NY10019, USA; gmt1@columbia.edu

Competing interests: none declared.

\section{REFERENCES}

1 Pauwels RA, Buist AS, Calverley PM, et al. Global strategy for diagnosis, management and prevention of chronic obstructive pulmonary disease: NHLBI/WHO Global Initiative for Chronic Obstructive Lung Disease (GOLD) Workshop Summary. Am J Respir Crit Care Med 2001;163:1256-76.

2 Cello BR, MacNee W. Standards for the diagnosis and treatment of patients with COPD: a summary of the ATS/ERS position paper. Eur Respir J 2004;23:932-46.

3 Boschetto P, Quintavalle S, Zeni E, et al. Association between markers of emphysema and more severe chronic obstructive pulmonary disease. Thorax 2006:61:1037-42.

4 Celli BR, Cote CG, Marin JM, et al. The body-mass index, airflow obstruction, dyspnea and exercise capacity index in chronic obstructive pulmonary disease. N Engl J Med 2004;350:1005-12.

5 Boschetto P, Miniati M, Miotto D, et al. Emphysema phenotype in chronic obstructive pulmonary disease patients. Eur Respir $J$ 2003;21:450-4.

6 Finlay GA, Russell KJ, McMahon KJ, et al Elevated levels of matrix metalloproteinases in bronchoalveolar lavage fluid of emphysematous patients. Thorax 1997;52:502-6.
7 Finlay GA, O'Driscoll LR, Russell KJ, et al. Matrix metalloproteinase expression and production by alveolar macrophages in emphysema. Am J Respir Crit Care Med 1997;156:240-7.

8 Bousquet J, Chanez P, Lacoste JY, et al. Eosinophilic inflammation in asthma. NEngl J Med 1990;323:1033-9.

9 Holgate ST. Reflection by the Chairman. Am Rev Respir Dis 1991;143:1175-6.

10 Barnes PJ, Chowdhury B, Kharitonov SA, et al Pulmonary biomarkers in chronic obstructive pulmonary disease. Am J Respir Crit Care Med 2006;174:6-14.

11 Saetta M, DiStefano A, Maestrelli P, et al. Airway eosinophilia in chronic bronchitis during exacerbations. Am J Respir Crit Care Med 1994; 150:1646-52.

12 Fujimoto K, Yasou M, Urushibata K, et al. Airway inflammation during stable and acutely exacerbated chronic obstructive pulmonary disease. Eur Respir J 2005;25:640-6.

13 Louis RE, Cataldo D, Buckley MG, et al. Evidence of mast-cell activation in a subset of patients with eosinophilic chronic obstructive pulmonary disease. Eur Respir 2002;20:325-31.

14 Brightling CE, Monteiro W, Ward R, et al. Sputum eosinophilia and short-term response to prednisolone in chronic obstructive pulmonary disease: a randomized controlled trial. Lancet 2000;356: 1480

15 Brightling CE, McKenna S, Hargadon B, et al. Sputum eosinophilia and the short term response to inhaled mometasone in chronic obstructive pulmonary disease. Thorax 2005;60:193-8.

16 Saetta M, Turato G, Maestrelli $P$, et al. Cellular and structural bases of chronic obstructive pulmonary disease. Am J Respir Crit Care Med 2001;163:1304-9.

17 Barnes PJ, Shapiro SD, Pauwels RA. Chronic obstructive pulmonary disease: molecular and cellular mechanisms. Eur Respir J 2003;22:672-88

18 O'Connor CM, FitzGerald MX. Matrix metalloproteases and lung disease. Thorax 1994:49:101-8

19 Shapiro SD. Proteinases in chronic obstructive pulmonary disease. Biochem Soc Trans 2002;30:98-102.

20 Sires UI, Murphy G, Baragi VM, et al. Matrilysin is much more efficient than other matrix metalloproteinases in the proteolytic inactivation of alpha 1-antitrypsin. Biochem Biophys Res Commun 1994;204:613-20.

21 Fabbri LM, Romagnoli M, Corbetta L, et al. Differences in airway inflammation in patients with fixed airflow obstruction due to asthma or chronic obstructive pulmonary disease. Am J Respir Crit Care Med 2003;167:418-24.

\section{Underdiagnosed chronic obstructive pulmonary disease in England: new country, same story}

\section{M Mannino}

\section{Underdiagnosis or misdiagnosis of COPD is a problem in England too}

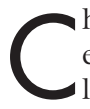
onic obstructive pulmonary disease (COPD) remains one of the emerging as increasingly important in the developing world. Despite its importance, COPD is not well recognised by the general public and frequently goes undiagnosed in people who have evidence of it. This underdiagnosis of people with evidence of obstruction on spirometry (generally adults with an $\mathrm{FEV}_{1} / \mathrm{FVC}$ ratio $<70 \%$ ) has been previously documented in the United States ${ }^{1}$ and Korea. ${ }^{2}$

The paper by Shahab and colleagues in this issue of Thorax shows that underdiagnosis and, in all likelihood, misdiagnosis, is a factor in England also. ${ }^{3}$ Their key finding was that $13.3 \%$ of the population aged 35 and older had evidence of COPD that would, in general, correspond to GOLD stage 1 or more severe disease. ${ }^{4}$ Bronchodilator response was not evaluated, so this would not meet strict GOLD criteria and, if this population is similar to the Norwegian adult population, ${ }^{5}$ one might expect the "post-bronchodilator" prevalence of COPD to be 20-25\% lower. 